Research Article

\title{
Finite Element Analysis of Surrounding Rock with a Thermal Insulation Layer in a Deep Mine
}

\author{
Hao Wang $(\mathbb{D}$ and Qianyu Zhou \\ School of Architecture and Environmental Engineering, Shenzhen Polytechnic, Shenzhen 518055, China \\ Correspondence should be addressed to Hao Wang; wanghao6755@126.com
}

Received 15 June 2020; Accepted 12 August 2020; Published 30 September 2020

Academic Editor: Akhil Garg

Copyright (C) 2020 Hao Wang and Qianyu Zhou. This is an open access article distributed under the Creative Commons Attribution License, which permits unrestricted use, distribution, and reproduction in any medium, provided the original work is properly cited.

\begin{abstract}
As the main heat source, surrounding rock heat dissipation is a very important factor in the prediction of mine climate conditions, especially in deep high-temperature mines. To reveal the heat control mechanism of surrounding rocks due to the thermal insulation of deep roadways, a mathematical model of the surrounding rocks around deep roadways with heat insulation was established with the finite element method, and a corresponding calculation program was developed. A series of results were determined to show how setting an insulation layer could affect the distribution law of the temperature field within and around tunnels. Therefore, rules of the variation in wall temperature and temperature gradient with thermal conductivity coefficients were obtained within and around tunnels. The heat release capacity of the surrounding rocks of the roadways is significantly reduced after introducing a thermal insulation layer into the roadway design under different schemes; these design schemes were determined by further engineering example analysis. It was found that the heat insulation layer design can cool the surrounding rocks of deep mine roadways.
\end{abstract}

\section{Introduction}

Over the years, the number of deep mines has been increasing rapidly worldwide. According to the relevant data statistics, a large number of mining companies are facing issues related to thermal disasters due to the increase in mining depth [1-4]. Compared to low-temperature environments, in high-temperature environments, the labor production rate is greatly reduced, and the health of coal miners is greatly endangered [5-8]. Therefore, reasonable cooling measures in coal mines are necessary to prevent deep mine roadways from being destroyed by thermal disaster accidents.

The thermal convection between the wall rock and the airflow for a high-temperature roadway in a deep mine is a very complicated unsteady-state process, and many scholars have done much research work on it. He considered the problems existing in coal mines and proposed HEMS cooling technology for the status, characteristics, and countermeasures of cooling in deep mines [9]. Krasnoshtein et al. presented mathematical relations of heat exchange between mine air and rock mass during fire [10]. The rock pressure and virgin rock temperature increase significantly with increasing mining depth. Sasmito et al. assessed the thermal management of underground mines by computational fluid dynamics (CFD) and the effects of cooling load, ventilation flow rate, and original rock temperature on thermal comfort [11]. Anderson and Souza proposed a method that may be considered by ventilation specialists to effectively implement a thermal management control system, and a case based on a detailed heat management assessment conducted for a potash mine in Saskatchewan, Canada, was introduced [12]. Zhang et al. used ANSYS software to simulate the velocity and temperature distribution of air in a pipe and discussed the insulation effect according to the ventilation of the heading face in a deep 
mine [13]. Habibi et al. carried out a stratigraphic thermal study on an active panel to determine rock properties when studying the influence of underground thermal change [14].

The heat dissipation capacity of the rock surrounding the roadway is very large due to the influence of the mining scale and the increase in the geothermal gradient [15]. Relevant research has shown that reducing the heat dissipation rate and the range of temperature disturbance of surrounding rocks can prevent the generation of thermal hazards. Unfortunately, neither the mechanism of heat dissipation of high-temperature roadways by insulation layers nor the application of cooling technology has been studied in detail. Relevant work urgently needs to be performed. It was proven that the finite element method was suitable for solving many thermal problems $[16,17]$. In this paper, an experimental platform for the heat control mechanism of surrounding rocks is established, and the corresponding mathematical model is constructed according to the finite element method. Simultaneously, the thermal insulation control mechanism for the surrounding rocks is also discussed and analyzed in detail from both experimental and simulation aspects. Finally, the effects of various insulation control measures will be discussed in conjunction with engineering examples.

\section{Experimental Section}

2.1. Experiment Rig. The schematic of the experimental rig is shown in Figure 1, which is mainly composed of three parts: air temperature control systems, similar simulation experiment systems, and temperature monitoring systems. The airflow temperature control system includes high- and lowtemperature airflow test box 1 , frequency conversion blower 2 , air inlet pipe 3 , and air return pipe 4 . A similar simulation experiment system includes the main body of roadway model 5, temperature sensor 6 , and similar simulation roadway 7 . The temperature monitoring system includes signal transmission line 8 , computer 9 , and data collector 10 .

The aim of the experiment is to analyze the law of temperature variation inside the similar material of roadway surrounding rock. Therefore, the experimental part of measuring the change in temperature of similar materials should be the main part of the surrounding rock experimental system of the tunnel. Considering all kinds of influencing factors, the size of the main body of the roadway model is determined to be $900 \times 900 \times 400 \mathrm{~mm}^{3}$, and the radius of the tunnel is $50 \mathrm{~mm}$. The distance between the temperature sensors is $25 \mathrm{~mm}$, as shown in Figure 2. The fresh airflow in the surrounding rock of the tunnel is provided by the high- and low-temperature airflow test box, as shown in Figure 3.

2.2. Experimental Materials. Generally, similar simulation materials have the characteristics of rapid molding, good uniformity, easy access, low cost, and convenient production. The similar simulation experiment in this paper involves the simulation of the temperature field of the surrounding rock of a roadway. Therefore, it is necessary to consider the thermal conductivity of common rocks in coal

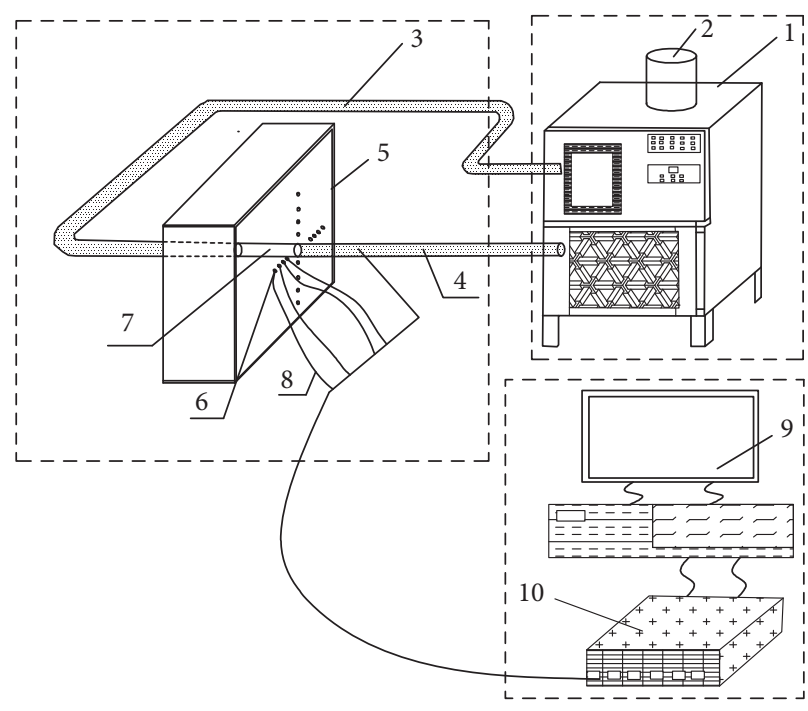

FIGURE 1: Sketch of the experiment rig.

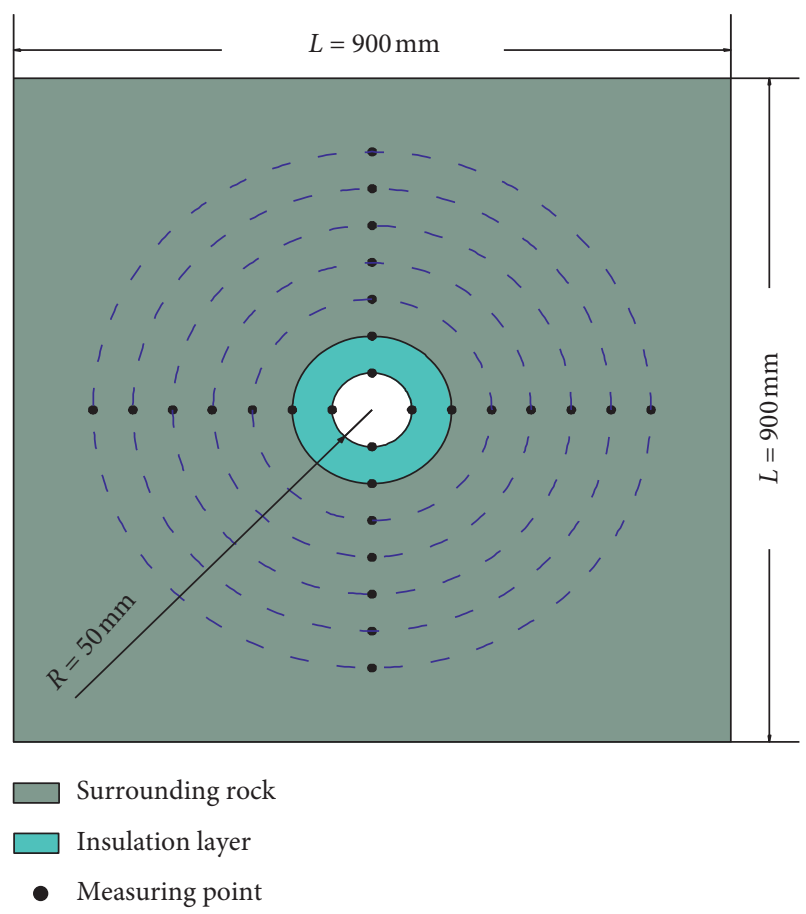

Figure 2: Measuring point arrangement.

measure strata and the thermal physical properties of materials when selecting similar materials.

Table 1 shows that the thermal conductivity of common rocks in coal-bearing strata is generally approximately $2 \mathrm{~W} /$ $\left(\mathrm{m} \cdot{ }^{\circ} \mathrm{C}\right)$. Therefore, sandstone powder is selected as a similar material to simulate the rock surrounding the roadway. In this paper, sandstone powder is selected to make similar surrounding rock materials. A thermal conductivity measuring instrument and specific heat capacity measuring instrument are used to measure the thermodynamic parameters of similar materials in the laboratory, as shown in Figures 4 and 5. 


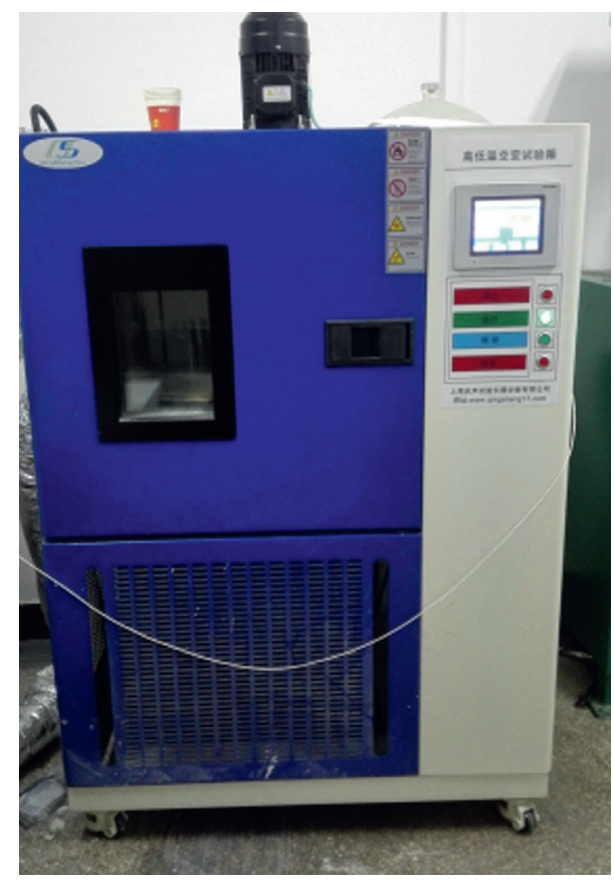

Figure 3: High- and low-temperature airflow test box.

TABle 1: Common thermophysical parameters of coal measure strata.

\begin{tabular}{lcccc}
\hline Parameters & Shale & Mudstone & Limestone & Unit \\
\hline Conductivity coefficient & 1.77 & 2.26 & 2.28 & $\begin{array}{c}\mathrm{W} / \\
\left(\mathrm{m} \cdot{ }^{\circ} \mathrm{C}\right)\end{array}$ \\
Density & 2570 & 2723 & 2679 & $\begin{array}{c}\mathrm{kg} / \mathrm{m}^{3} \\
\mathrm{~kJ} /\end{array}$ \\
Specific heat & 0.905 & 0.934 & 0.909 & $\left(\mathrm{~kg} \cdot{ }^{\circ} \mathrm{C}\right)$ \\
\hline
\end{tabular}

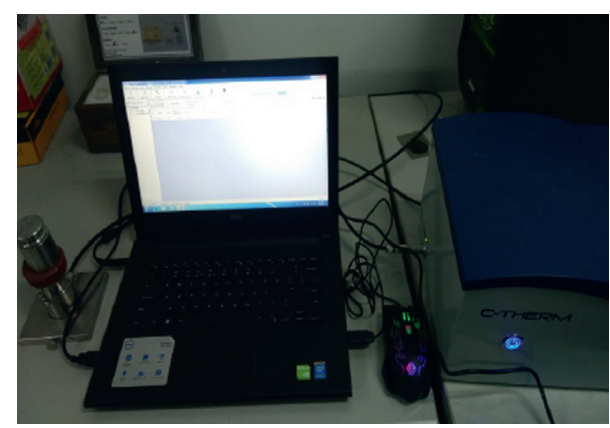

FIgURE 4: Thermal conductivity measuring instrument.

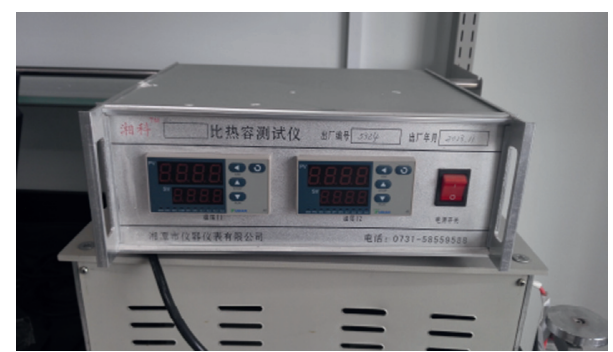

FIGURE 5: Specific heat capacity measuring instrument.
In addition, the main purpose of this experiment is to test the effect of the thermal insulation layer. Therefore, the thermal insulation layer is composed of similar materials with a small thermal conductivity. A similar insulation layer material is made by mixing gypsum with water in a certain proportion or by foam cement alone. Similar materials commonly used in experiments are shown in Figure 6. $\mathrm{Fe}_{2} \mathrm{O}_{3}$ powder as a conductive material can adjust the thermal conductivity of similar materials. To prepare experimental materials with a thermal conductivity that meets the experimental requirements, $\mathrm{Fe}_{2} \mathrm{O}_{3}$ powder with different contents is used to improve the thermal conductivity of gypsum. The specimens were prepared by the direct incorporation method, and the water consumption of the gypsum preparation standard consistency was 0.5. After molding, the specimens were cured at room temperature of $20^{\circ} \mathrm{C}$ for 24 hours and then dried in an incubator. Then, the specimens were tested after curing for 5 days under the conditions of an environmental humidity of $65 \%$ and $85 \%$. The proportioning scheme of the gypsum-containing similar materials was designed by orthogonal testing. The orthogonal experiment table $L_{4}\left(2^{3}\right)$ was used in the experiment. The factor level and experimental results are shown in Table 2.

In this paper, a foam cement block with small thermal conductivity is selected as another thermal insulation material. After groups of tests, the thermal conductivity of the similar surrounding rock made of sandstone powder and the thermal insulation layer made of foam cement block are $2.233 \mathrm{~W} /\left(\mathrm{m} \cdot{ }^{\circ} \mathrm{C}\right)$ and $0.19 \mathrm{~W} /\left(\mathrm{m} \cdot{ }^{\circ} \mathrm{C}\right)$, respectively. In addition, this paper uses the medium proportion scheme of Test 2 to make gypsum similar materials. Based on the above work, the experimental scheme for testing the thermal insulation effect is finally determined. The parameter values under the corresponding experimental scheme are shown in Table 3.

\subsection{Experimental Procedure}

(1) Using the direct pouring method to layer similar analog materials, the temperature sensors are arranged in the corresponding position, and the temperature sensors and data collector are connected.

(2) One side of the high- and low-temperature test chamber is equipped with two vents, and the ventilation pipe is connected to the air vent. At the same time, the variable frequency blower is installed on the top of the test chamber.

(3) The temperature probe and the computer are connected, and the test system software is installed on the computer to complete the temperature monitoring system setup.

(4) The test system, including the mechanical connections, power systems, and test systems, is checked to ensure that it is in good condition after completing the above system installation. 


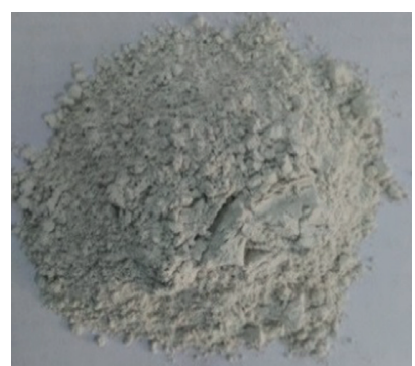

(a)

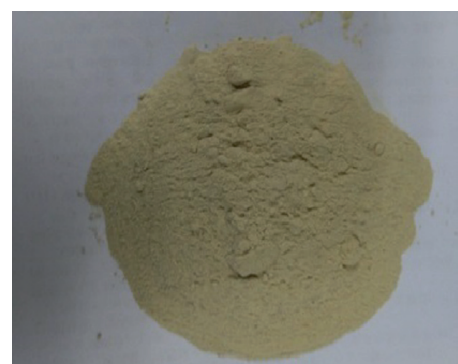

(b)

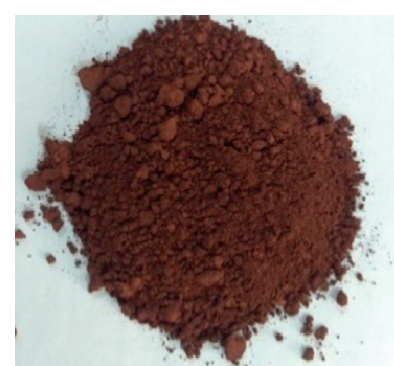

(c)

Figure 6: Simulation materials. (a) Gypsum. (b) Sandstone powder. (c) Iron oxide.

TABLE 2: Factor level table and test results.

\begin{tabular}{|c|c|c|c|c|c|}
\hline Parameters & Test 1 & Test 2 & Test 3 & Test 4 & Unit \\
\hline Humidity of curing environment & 65 & 65 & 85 & 85 & $\%$ \\
\hline Mass fraction of iron powder & 0.6 & 0.8 & 0.6 & 0.8 & $\%$ \\
\hline Test ambient temperature & 17.5 & 20 & 20 & 17.5 & ${ }^{\circ} \mathrm{C}$ \\
\hline Conductivity coefficient & 0.619 & 0.673 & 0.625 & 0.658 & $\mathrm{~W} /\left(\mathrm{m} \cdot{ }^{\circ} \mathrm{C}\right)$ \\
\hline
\end{tabular}

TABLE 3: Experimental scheme.

\begin{tabular}{|c|c|c|c|c|c|}
\hline Parameters & Symbol & Scheme 1 & Scheme 2 & Scheme 3 & Unit \\
\hline Conductivity coefficient of surrounding rocks & $\lambda_{1}$ & 2.233 & 2.233 & 2.233 & $\mathrm{~W} /\left(\mathrm{m} \cdot{ }^{\circ} \mathrm{C}\right)$ \\
\hline Thermal diffusivity of surrounding rocks & $a_{1}$ & 1.109 & 1.109 & 1.109 & $10^{-6}\left(\mathrm{~m}^{2} / \mathrm{s}\right)$ \\
\hline Conductivity coefficient of the insulation layer & $\lambda_{2}$ & 2.233 & 0.673 & 0.19 & $\mathrm{~W} /\left(\mathrm{m} \cdot{ }^{\circ} \mathrm{C}\right)$ \\
\hline Thermal diffusivity of the insulation layer & $a_{2}$ & 1.109 & 0.6669 & 0.3619 & $10^{-6}\left(\mathrm{~m}^{2} / \mathrm{s}\right)$ \\
\hline
\end{tabular}

(5) The set parameters are input into the instrument according to the test contents after the high- and low-temperature test chamber and frequency conversion fan are opened. The experimental data are saved after the experiment is completed.

(6) A new experiment is started after adjusting the experimental scheme.

\section{Construction of the Finite Element Model}

In recent decades, numerical simulation methods have become an effective way to solve heat transfer problems $[18,19]$. In this paper, the finite element method is used to establish the thermal insulation mathematical model for the temperature field of roadway surrounding rock. The heat exchange between the wall rock and the airflow is extremely complicated, so it is necessary to make some assumptions as follows. It is first assumed that the temperature field of the surrounding rocks of the roadway without an internal heat source is homogeneous and isotropic. The temperature gradient does not change significantly along the axis of the tunnel, and the heat transfer conditions are the same. The roadway cross section is round, and the internal temperature of the surrounding rocks far from the wall face is the virgin rock temperature. Therefore, the problem can be simplified without causing a significant difference in the calculation of the temperature field. Based on the above analysis, the heat conduction differential equation and its boundary condition are established for the surrounding rock temperature field according to the conservation of energy and Fourier's law:

$$
\left\{\begin{array}{l}
\frac{\partial T}{\partial \tau}=\frac{\lambda}{\rho c}\left(\frac{\partial^{2} T}{\partial x^{2}}+\frac{\partial^{2} T}{\partial y^{2}}\right), \\
T_{\tau=0}=T_{g u}, \\
-\left.\lambda \frac{\partial T}{\partial r}\right|_{\Gamma_{1}}=h\left(T_{w}-T_{f}\right), \\
T_{\Gamma_{2}}=T_{g u},
\end{array}\right.
$$

where $\lambda$ is the heat conductivity coefficient of the surrounding rocks, $\mathrm{W} /\left(\mathrm{m} \cdot{ }^{\circ} \mathrm{C}\right) ; \rho$ is the surrounding rock density, $\mathrm{kg} / \mathrm{m}^{3} ; c$ is the specific heat at constant pressure, $\mathrm{J} /$ $(\mathrm{kg} \cdot \mathrm{K}) ; T_{\tau=0}$ is the initial rock temperature, ${ }^{\circ} \mathrm{C} ; T_{q u}$ is the virgin rock temperature, ${ }^{\circ} \mathrm{C} ; \Gamma_{1}$ is the third boundary condition of the wall face; $\Gamma_{2}$ is the Dirichlet boundary condition of the surrounding rocks far from the wall face; $T_{w}$ is the wall rock temperature, ${ }^{\circ} \mathrm{C}$; and $T_{f}$ is the airflow temperature, ${ }^{\circ} \mathrm{C}$.

The mathematical description of the above temperature field is a partial differential equation, and it cannot be solved by an analytic method. Therefore, the finite element method is adopted to solve the above problem. If the calculated area $D$ is divided into $E$ units and $n$ nodes, then the distribution of 


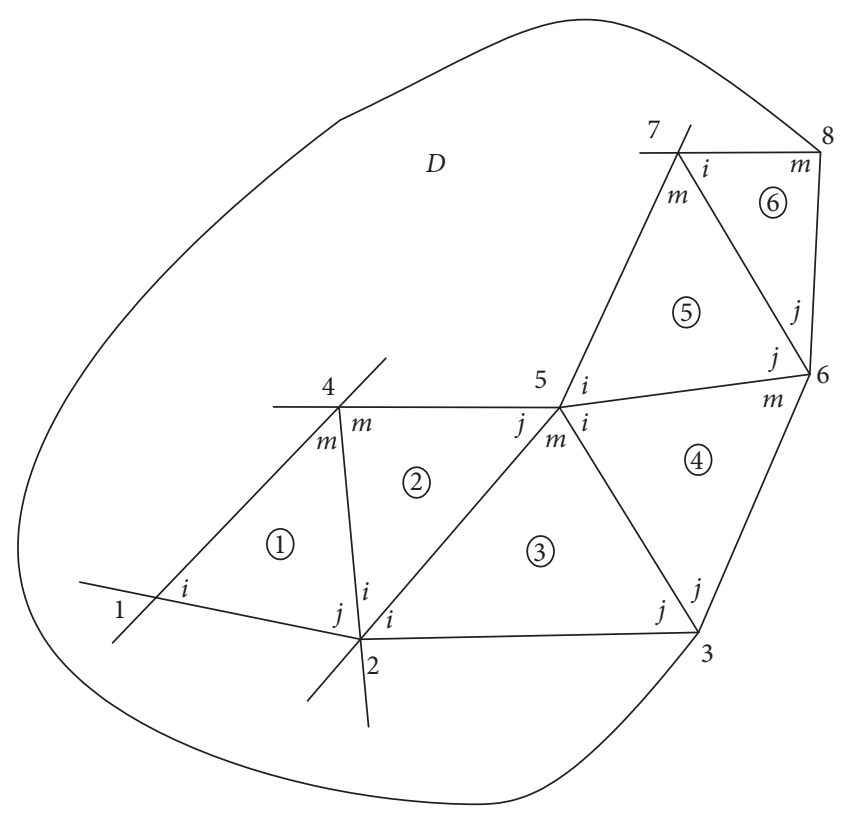

FIgURE 7: Unit partitioning of the computational region.

the surrounding rock temperature can be discretized into the undetermined temperature values of $n$ nodes, as shown in Figure 7. The variational computation can be carried out in the element, so the basic finite element formula can be obtained according to the variational principle:

$$
\begin{aligned}
\frac{\partial J^{e}}{\partial T_{l}}= & \iint_{e}\left[\lambda\left(\frac{\partial W_{l}}{\partial x} \frac{\partial T}{\partial x}+\frac{\partial W_{l}}{\partial y} \frac{\partial T}{\partial y}\right)\right. \\
& \left.+\rho c W_{l} \frac{\partial T}{\partial \tau}\right] \mathrm{d} x \mathrm{~d} y, \quad(l=i, j, m),
\end{aligned}
$$

where the superscript or subscript $e$ represents the units; $i, j$, and $m$ are the three vertices of the triangular element; and subscript $l$ denotes the node number.

$W_{l}$ is a weighted function, according to the Galerkin method:

$$
W_{l}=\frac{\partial T}{\partial T_{l}} ; \quad(l=i, j, m) .
$$

According to the calculation formula of the temperature interpolation function for the finite element method [20], the following formulas are deduced:

$$
\begin{aligned}
\frac{\partial W_{i}}{\partial x} & =\frac{b_{i}}{2 S}, \\
\frac{\partial W_{i}}{\partial y} & =\frac{c_{i}}{2 S}, \\
\frac{\partial T}{\partial x} & =\frac{\left(b_{i} T_{i}+b_{j} T_{j}+b_{m} T_{m}\right)}{2 S}, \\
\frac{\partial T}{\partial y} & =\frac{\left(c_{i} T_{i}+c_{j} T_{j}+c_{m} T_{m}\right)}{2 S}, \\
\frac{\partial T}{\partial \tau} & =N_{i} \frac{\partial T_{i}}{\partial \tau}+N_{j} \frac{\partial T_{j}}{\partial \tau}+N_{m} \frac{\partial T_{m}}{\partial \tau} .
\end{aligned}
$$

Equation (4) is substituted into equation (2), so equation (2) can be written as follows:

$\frac{\partial J^{e}}{\partial T_{i}}=\frac{\lambda}{4 S}\left[\left(b_{i}^{2}+c_{i}^{2}\right) T_{i}+\left(b_{i} b_{j}+c_{i} c_{j}\right) T_{j}+\left(b_{i} b_{m}+c_{i} c_{m}\right) T_{m}\right]+\rho c$

$\left[\frac{\partial T_{i}}{\partial \tau} \iint_{e} N_{i}^{2} \mathrm{~d} x \mathrm{~d} y+\frac{\partial T_{j}}{\partial \tau} \iint_{e} N_{i} N_{j} \mathrm{~d} x \mathrm{~d} y+\frac{\partial T_{m}}{\partial \tau} \iint_{e} N_{i} N_{m} \mathrm{~d} x \mathrm{~d} y\right]=\frac{\lambda}{4 S}\left[\left(b_{i}^{2}+c_{i}^{2}\right) T_{i}+\left(b_{i} b_{j}+c_{i} c_{j}\right) T_{j}+\left(b_{i} b_{m}+c_{i} c_{m}\right) T_{m}\right]+\frac{\rho c S}{12}\left(2 \frac{\partial T_{i}}{\partial \tau}+\frac{\partial T_{j}}{\partial \tau}+\frac{\partial T_{m}}{\partial \tau}\right)$.

In the same way, the contribution of each unit to nodes $j$ and $m$ can be deduced:

$$
\begin{gathered}
\frac{\partial J^{e}}{\partial T_{j}}=\frac{\lambda}{4 S}\left[\left(b_{i} b_{j}+c_{i} c_{j}\right) T_{i}+\left(b_{j}^{2}+c_{j}^{2}\right) T_{j}+\left(b_{j} b_{m}+c_{j} c_{m}\right) T_{m}\right]+\frac{\rho c S}{12}\left(\frac{\partial T_{i}}{\partial \tau}+2 \frac{\partial T_{j}}{\partial \tau}+\frac{\partial T_{m}}{\partial \tau}\right), \\
\frac{\partial J^{e}}{\partial T_{m}}=\frac{\lambda}{4 S}\left[\left(b_{i} b_{m}+c_{i} c_{m}\right) T_{i}+\left(b_{j} b_{m}+c_{j} c_{m}\right) T_{j}+\left(b_{m}^{2}+c_{m}^{2}\right) T_{m}\right]+\frac{\rho c S}{12}\left(\frac{\partial T_{i}}{\partial \tau}+\frac{\partial T_{j}}{\partial \tau}+2 \frac{\partial T_{m}}{\partial \tau}\right) .
\end{gathered}
$$


To program the calculation program, equations (5), (6), and (7) are converted into matrix forms to be expressed as

$$
\left\{\begin{array}{c}
\frac{\partial J^{e}}{\partial T_{i}} \\
\frac{\partial J^{e}}{\partial T_{j}} \\
\frac{\partial J^{e}}{\partial T_{m}}
\end{array}\right\}=\left[\begin{array}{ccc}
k_{i i} & k_{i j} & k_{i m} \\
k_{j i} & k_{j j} & k_{j m} \\
k_{m i} & k_{m j} & k_{m m}
\end{array}\right]\left\{\begin{array}{c}
T_{i} \\
T_{j} \\
T_{m}
\end{array}\right\}+\left[\begin{array}{ccc}
n_{i i} & n_{i j} & n_{i m} \\
n_{j i} & n_{j j} & n_{j m} \\
n_{m i} & n_{m j} & n_{m m}
\end{array}\right]\left\{\begin{array}{c}
\frac{\partial T_{i}}{\partial \tau} \\
\frac{\partial T_{j}}{\partial \tau} \\
\frac{\partial T_{m}}{\partial \tau}
\end{array}\right\},
$$

where

$$
\begin{aligned}
& k_{l l}=\frac{\lambda}{4 S}\left(b_{l}^{2}+c_{l}^{2}\right), \\
& k_{\ln }=k_{n l}=\frac{\lambda}{4 S}\left(b_{l} b_{n}+c_{l} c_{n}\right), \\
& n_{l l}=\frac{S \rho c}{6} \\
& n_{\ln }=n_{n l}=\frac{S \rho c}{12} \\
& (l, n=i, j, m ; l \neq n) .
\end{aligned}
$$

When the symbol $m$ is the internal node of the computational region, the boundary nodes of the element are represented by the symbols $i$ and $j$. Therefore, the contribution of the internal triangular element to any node is calculated using the above method. Similarly, the contribution of each boundary element to the corresponding boundary node is calculated and represented as a matrix as follows:

$$
\left[\begin{array}{c}
\theta_{i} \\
\theta_{j}
\end{array}\right]=\left[\begin{array}{ll}
u_{i i} & u_{i j} \\
u_{j i} & u_{j j}
\end{array}\right]\left[\begin{array}{c}
T_{i} \\
T_{j}
\end{array}\right]+\left[\begin{array}{c}
v_{i} \\
v_{j}
\end{array}\right],
$$

where

$$
\begin{aligned}
& u_{i i}=u_{j j}=\frac{h S}{3}, \\
& u_{i j}=u_{j i}=\frac{h S}{6}, \\
& v_{i}=v_{j}=\frac{h S T_{f}}{2} .
\end{aligned}
$$

By solving the above equations, the temperature values of all the nodes in the discrete region can be calculated, and the temperature field can be obtained. Taking the ventilation time of 3 hours of Scheme 1 in Table 1 as an example, the transient temperature contours obtained by the above methods are shown in Figure 7.

As shown in Figure 8, the temperature of the wall face begins to decrease after ventilation begins, and the temperature contours extend outward in the form of concentric

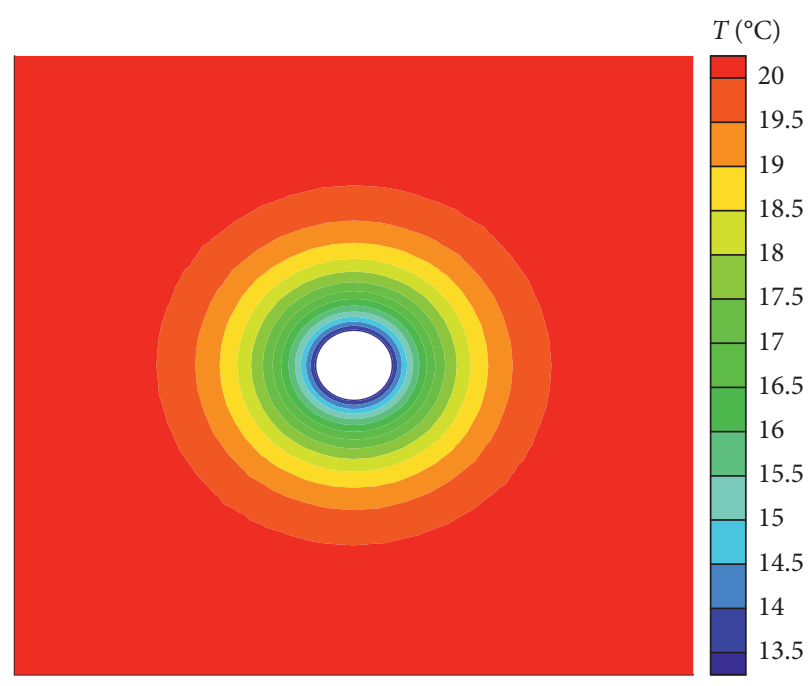

Figure 8: Transient temperature contours.

circles. The temperature in the deep surrounding rocks is not affected by the decrease in the temperature of the wall face and maintain the virgin temperature.

\section{Results and Discussion}

4.1. Finite Element Method Calculation Results. To ensure the accuracy of the experimental results, the change in the temperature field in three hours is taken as an example. The finite element method is used to calculate the results for the three schemes in Table 1, and the obtained results are plotted with Tecplot software for comparative analysis.

As shown in Figure 9, the temperature at the wall surface decreases sequentially from (a) to (c). The wall temperature in Scheme 1 is approximately $13.5^{\circ} \mathrm{C}$, while the wall temperature in Scheme 3 is reduced to approximately $7^{\circ} \mathrm{C}$. In addition, the temperature disturbance range decreases in turn from (a) to (c). The temperature disturbance range in Scheme 1 is approximately $0.26 \mathrm{~m}$, while the disturbance range of temperature in Scheme 3 is reduced to approximately $0.21 \mathrm{~m}$.

There is no insulation system in Scheme 1, unlike in Scheme 2 and Scheme 3. The results show that the temperature of the wall face and the temperature disturbance range of the surrounding rocks are greatly reduced due to the effect of the thermal insulation layer.

4.2. Characteristics of the Temperature Distribution in the Roadway. To verify the correctness of the finite element simulation results, the experimental results of the temperature field of the surrounding rocks within 0.1 hours, 0.5 hours, 1 hour, and 3 hours are selected and compared with the simulation results, as shown in Figures 9(a)10(d).

Figure 10 shows that the general distribution characteristics of the temperature field with the heat insulation layer (Scheme 2 and Scheme 3) are consistent with those of the temperature field without the insulation layer (Scheme 


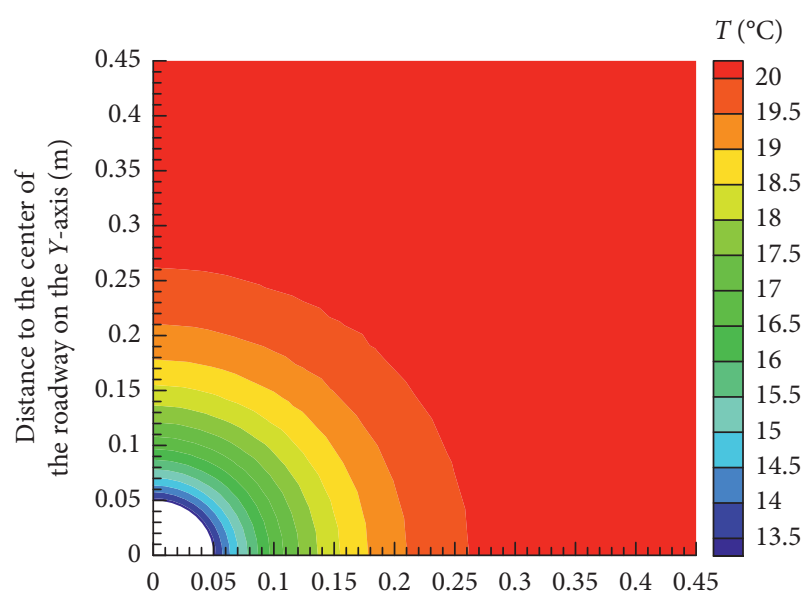

Distance to the center of the roadway on the $X$-axis (m)

(a)

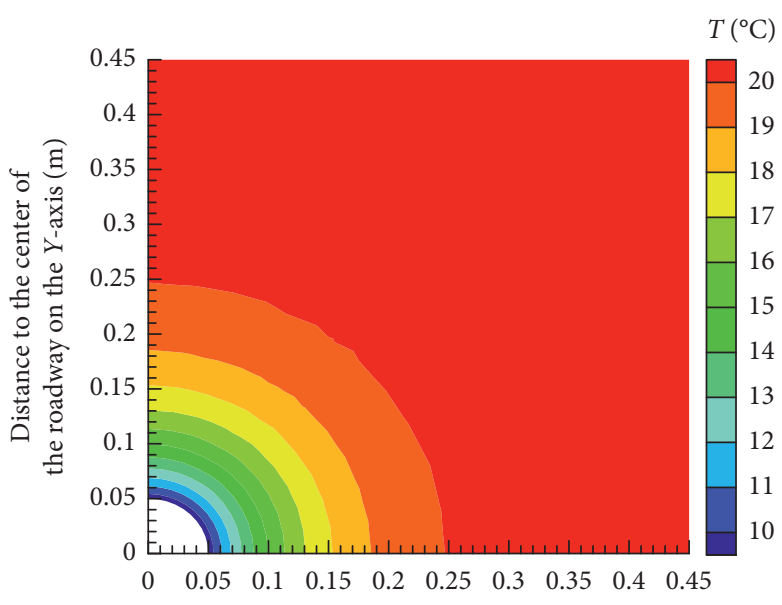

Distance to the center of the roadway on the $X$-axis (m)

(b)

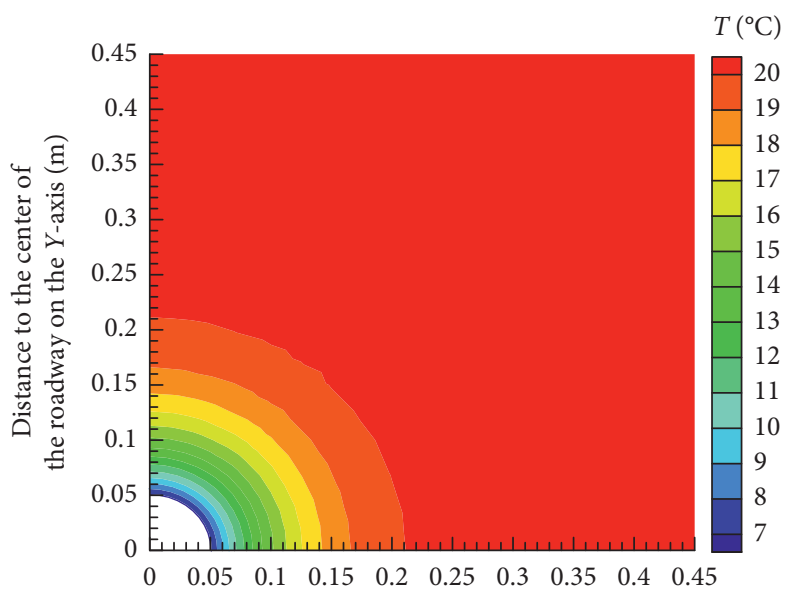

Distance to the center of the roadway on the $X$-axis (m)

(c)

Figure 9: Three-hour cloud chart. (a) Scheme 1. (b) Scheme 2. (c) Scheme 3.

1). The temperature gradually increases with increasing distance in the radial direction. At the wall face, the wall temperature gradually decreases as the conductivity of the insulation layer decreases. Due to the influence of the thermal insulation layer, the temperature of the surrounding rocks with the insulation layer is higher than that of the surrounding rocks without the insulation layer after an intersection of curves when the curve extends to the internal temperature field of the surrounding rocks. In addition, the experimental values are roughly distributed on the curve calculated by the finite element method, and their results validate each other.

\subsection{Variation Law of the Temperature Gradient in the Tem-} perature Field. As shown in Figure 11, near the wall face, the smaller the conductivity coefficient of the insulation layer is, the larger the temperature gradient is. When the curve extends to a certain position inside the surrounding rocks, the smaller the conductivity coefficient of the insulation layer is, the smaller the temperature gradient is.
4.4. Variation Law of the Temperature of the Wall Face with Time. As shown in Figure 12, the wall temperature of the road under the three schemes shows a decreasing trend to varying degrees after the start of ventilation. The reduction range of Scheme 1 is the smallest. The reduction range of the wall temperature increases with the decrease in the conductivity coefficient of the insulating layer, and its reduction range reaches a maximum under Scheme 3. Similarly, the rate of change in the curves of each scheme follows the above law; that is, this rate is the lowest for Scheme 1 and the highest for Scheme 3. In addition, the experimental results are basically consistent with the finite element method results, and the trends of both curves are consistent.

\subsection{Analysis of the Thermal Insulation Effect for Engineering} Example Applications. The main purpose of analyzing the heat control mechanism of the surrounding rocks with heat insulation in the roadway is to reduce the heat dissipation capacity and control the thermal hazard of the surrounding rocks of the deep roadway. Here, a circular tunnel with a 

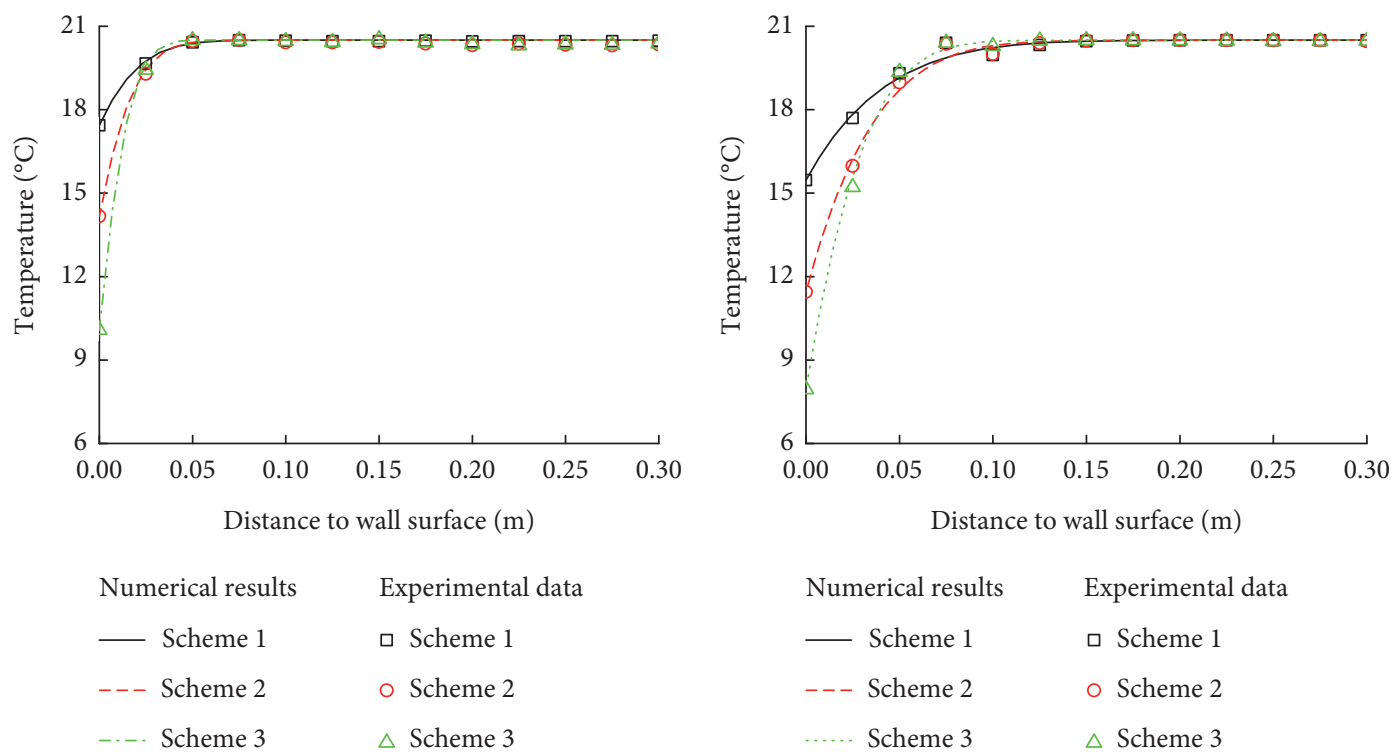

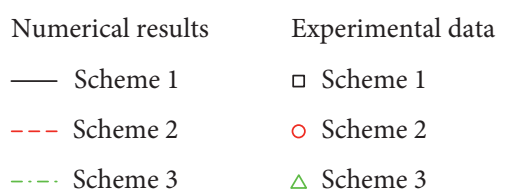

(a)

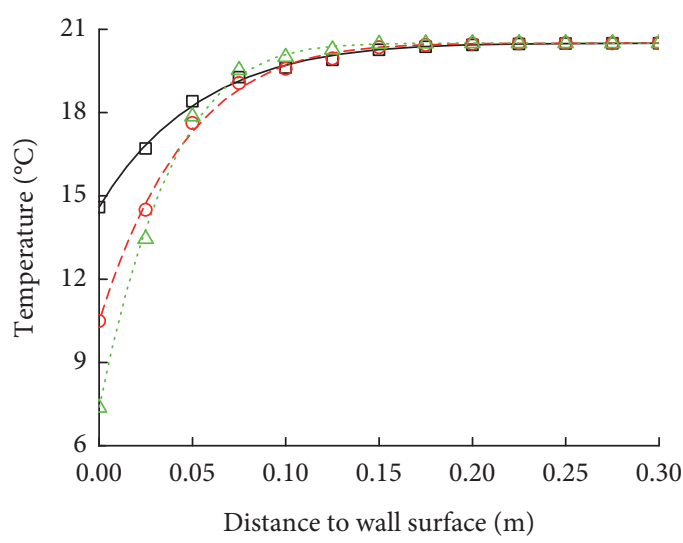

Numerical results

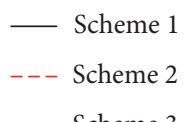

Experimental data

Scheme 1

○ Scheme 2

$\triangle$ Scheme 3

(c) (b)

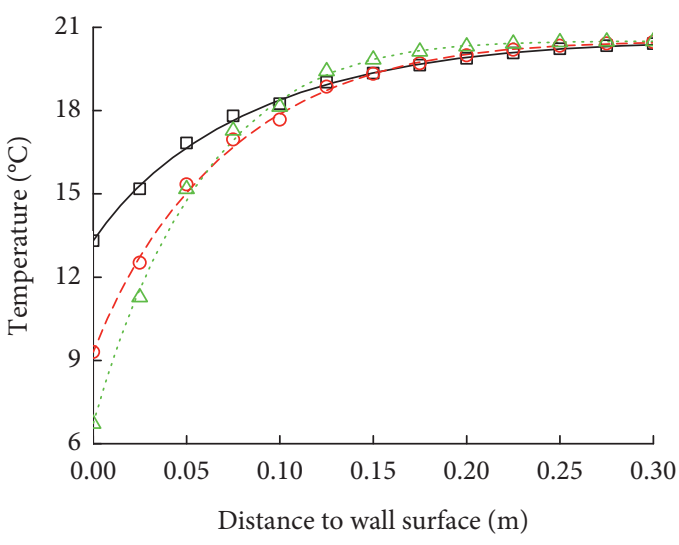

$\begin{array}{ll}\text { Numerical results } & \text { Experimental data } \\ - \text { Scheme 1 } & \square \text { Scheme 1 } \\ --- \text { Scheme 2 } & \circ \text { Scheme 2 } \\ \text {..... Scheme 3 } & \triangle \text { Scheme 3 }\end{array}$

(d)

FIGURE 10: Internal temperature field of surrounding rocks. (a) $0.1 \mathrm{H}$. (b) $0.5 \mathrm{H}$. (c) $1 \mathrm{H}$. (d) $3 \mathrm{H}$.

radius of $2 \mathrm{~m}$ is taken as an example to illustrate the heat dissipation law of surrounding rocks. The airflow velocity in the roadway is $3 \mathrm{~m} / \mathrm{s}$. The excess temperature of the virgin rock relative to the airflow temperature is $13^{\circ} \mathrm{C}$. The order of the structure from the roadway wall is the insulation layer, the concrete layer, and the rock stratum. The thermal physical parameters and calculation scheme of the surrounding rocks are shown in Table 4.

In this paper, the wall temperature of the surrounding rocks of the roadway obtained by the finite element method and the Newton cooling formula is used to calculate the thermal dissipation capacity of the surrounding rocks for the insulated roadway. The wall temperature changes sharply in the initial heat dissipation stage after ventilation. The heat-dissipating capacity of the surrounding rocks varies greatly during this unsteady process. To improve the calculation accuracy, we divided the time of the unsteady state process of the temperature field into a geometric progression. The whole time is divided into $n$ segments, and the heat dissipation capacity of the surrounding rocks at each time was thus represented as $Q_{1}, Q_{2}, \ldots, Q_{n}$. The total time was $L$, and the time of each period was $L_{1}, L_{2}, \ldots, L_{3}$.

As shown in Figure 13, the thermal dissipation of the surrounding rocks enters a relatively stable stage after 3 years of ventilation. The conductivity coefficient of the insulation layer decreases successively from Scheme 1 to Scheme 3 . The heat dissipation capacity of the surrounding rocks of the roadway is significantly reduced when the heat insulation layer is as designed in Scheme 3. 


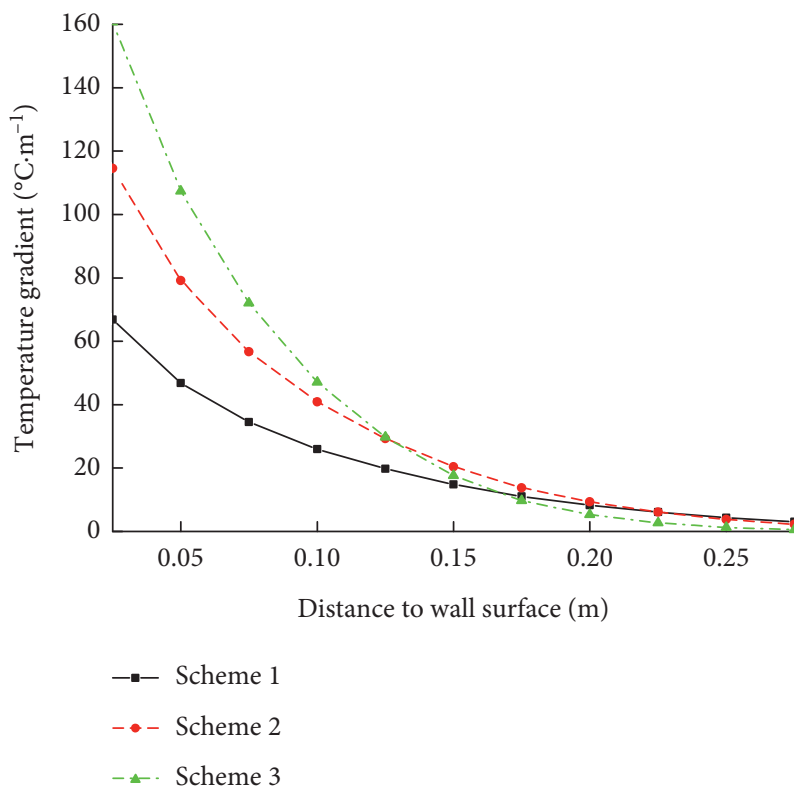

FIGURE 11: Variation law of the temperature gradient.

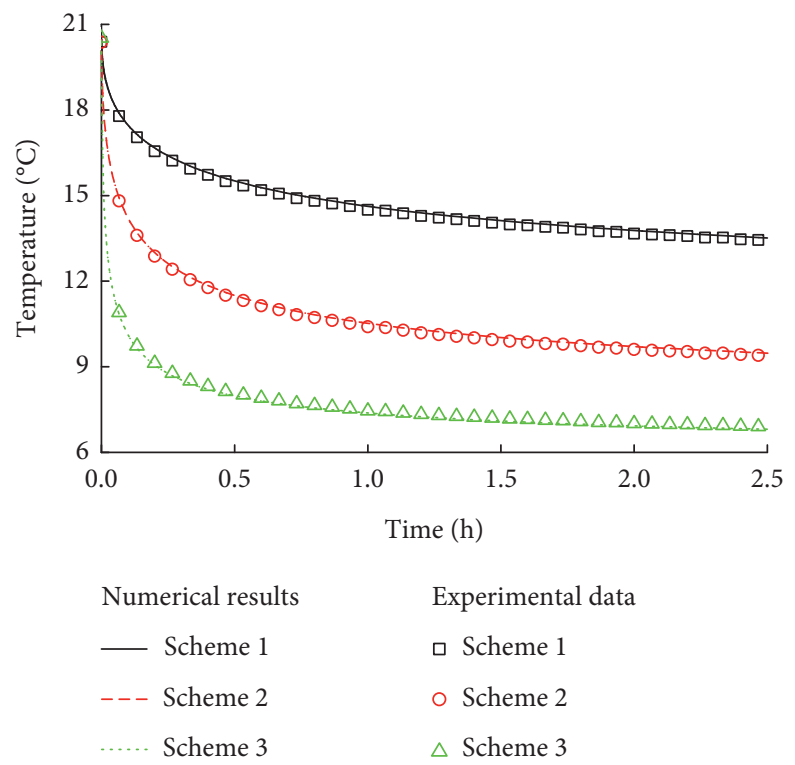

FIGURE 12: Comparison of the variation laws for wall temperature.

TABle 4: Calculation scheme.

\begin{tabular}{|c|c|c|c|c|}
\hline Parameters & Scheme 1 & Scheme 2 & Scheme 3 & Unit \\
\hline Conductivity coefficient of stratum $(\lambda)$ & 2.64 & 2.64 & 2.64 & $\mathrm{~W} /\left(\mathrm{m} \cdot{ }^{\circ} \mathrm{C}\right)$ \\
\hline Thermal diffusivity of stratum $(a)$ & 1.13 & 1.13 & 1.13 & $10^{-6}\left(\mathrm{~m}^{2} / \mathrm{s}\right)$ \\
\hline Conductivity coefficient of the concrete layer $(\lambda)$ & None & 1.51 & 1.51 & $\mathrm{~W} /\left(\mathrm{m} \cdot{ }^{\circ} \mathrm{C}\right)$ \\
\hline Thermal diffusivity of the concrete layer $(a)$ & None & 0.7136 & 0.7136 & $10^{-6}\left(\mathrm{~m}^{2} / \mathrm{s}\right)$ \\
\hline Thickness of concrete layer $(L)$ & None & 0.1 & 0.1 & $\mathrm{~m}$ \\
\hline Conductivity coefficient of insulation layer $(\lambda)$ & 2.64 & 0.76 & 0.23 & $\mathrm{~W} /\left(\mathrm{m} \cdot{ }^{\circ} \mathrm{C}\right)$ \\
\hline Thermal diffusivity of insulation layer $(a)$ & 1.13 & 0.4825 & 0.4319 & $10^{-6}\left(\mathrm{~m}^{2} / \mathrm{s}\right)$ \\
\hline Insulating material & None & Lime gypsum mortar & Coalgangue block + Expanded perlite & None \\
\hline Insulation layer thickness $(L)$ & None & 0.18 & 0.18 & $\mathrm{~m}$ \\
\hline
\end{tabular}




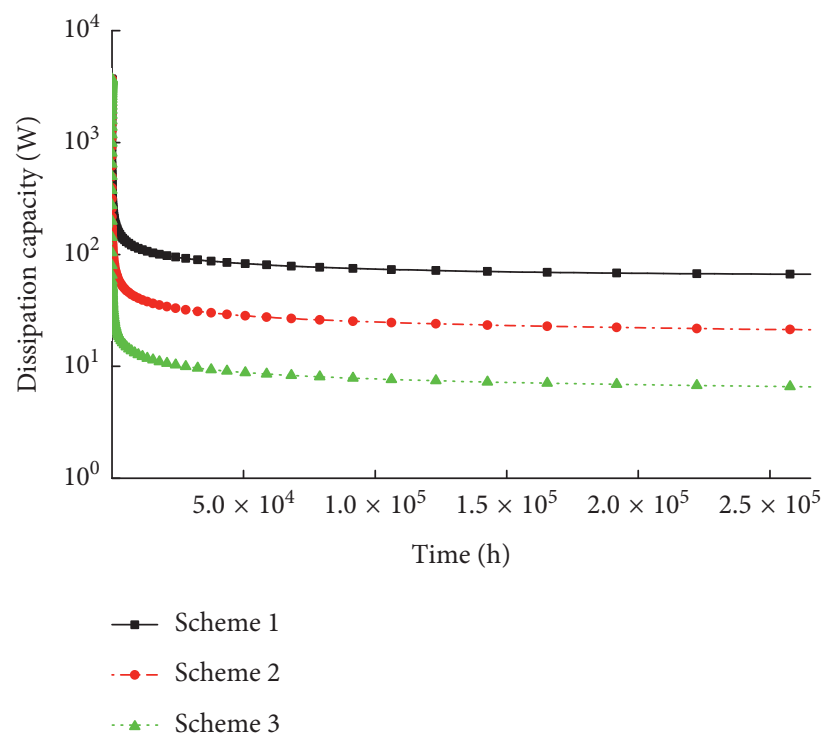

FIGURE 13: Variation curves of the dissipation capacity of the surrounding rocks with unit length.

TABLE 5: Emission reduction ratio with an insulation layer relative to that with no insulation layer.

\begin{tabular}{lcc}
\hline Time & Emission reduction ratio of scheme 2 (\%) & Emission reduction ratio of scheme 3 (\%) \\
\hline 1 day & 11.62 & 65.87 \\
1 month & 54.14 & 84.99 \\
1 year & 60.95 & 87.61 \\
10 years & 64.48 & 88.91 \\
20 years & 65.33 & 89.21 \\
30 years & 65.89 & 89.41 \\
\hline
\end{tabular}

To accurately calculate the average emission reduction ratio under the three schemes, we use the weighted average method to calculate the heat dissipation capacity of the surrounding rocks, as shown in

$Q_{m}=\frac{\left(\left(Q_{1}+Q_{2}\right) / 2\right) L_{1}+\left(\left(Q_{2}+Q_{3}\right) / 2\right) L_{2}+\cdots+\left(\left(Q_{n}+Q_{n+1}\right) / 2\right) L_{n}}{L}$.

Table 5 shows the emission reduction ratios at different time points under the two schemes. The designs of Scheme 2 and Scheme 3 showed good emission reduction effects. The emission reduction ratio reaches $84.99 \%$ in one month of ventilation, $87.61 \%$ in one year, and $89.41 \%$ in thirty years when the heat insulation layer is as designed in Scheme 3. Therefore, the construction of a heat insulation layer is very effective in reducing the heat dissipation capacity of surrounding rocks.

\section{Conclusions}

(1) A mathematical model of surrounding rocks with heat insulation around deep roadways was established with the finite element method. Experimental results were used to verify the numerical results, and these results agreed well.

(2) The wall temperature and the disturbance range of the temperature of the surrounding rocks are greatly reduced due to the effect of the thermal insulation layer. Near the wall face, the smaller the conductivity coefficient of the insulation layer is, the lower the wall temperature is, and the larger the temperature gradient is. Within the surrounding rocks far from the wall face, the smaller the conductivity coefficient of the insulation layer is, the higher the temperature of the surrounding rocks is, and the smaller the temperature gradient is. In addition, the numerical analysis of the variation law of the temperature of the wall face with time shows that the smaller the conductivity coefficient of the insulation layer is, the larger the reduction range of the wall temperature and the rate of change in the curves is.

(3) The heat dissipation capacity of the surrounding rocks of the roadway is significantly reduced when the heat insulation layer is introduced into the design of the roadway. It is explained in detail in this paper that this heat insulation layer design can cool the surrounding rock of deep mine roadways.

\section{Data Availability}

The data used to support the findings of this study are included within the article. 


\section{Conflicts of Interest}

The authors declare that there are no conflicts of interest.

\section{Acknowledgments}

This work has been financially funded by the Natural Science Foundation of China (Grant number: 51574249).

\section{Supplementary Materials}

The supplementary material consists of three parts: one for related data and the other two for related graphics. (Supplementary Materials)

\section{References}

[1] H. P. Xie, H. W. Zhou, D. J. Xue, H. W. Wang, R. Zhang, and F. Gao, "Research and consideration on deep coal mining and critical mining depth," Journal of China Coal Society, vol. 37, no. 4, pp. 535-542, 2012.

[2] H. Yan, F. He, T. Yang, L. Li, S. Zhang, and J. Zhang, "The mechanism of bedding separation in roof strata overlying a roadway within a thick coal seam: a case study from the Pingshuo Coalfield, China," Engineering Failure Analysis, vol. 62, pp. 75-92, 2016.

[3] G. E. Plessis, L. Liebenberg, and E. H. Mathews, "Case study: the effects of a variable flow energy saving strategy on a deepmine cooling system," Applied Energy, vol. 36, no. 1, pp. 101-104, 2012.

[4] S. J. Luo, X. F. Wang, F. Liu, L. Yan, and Y. Xie, "Some key problems and technical countermeasures for deep mining," Coal Technology, vol. 33, no. 11, pp. 309-311, 2014.

[5] M. Sunkpal, P. Roghanchi, and K. C. Kocsis, "A method to protect mine workers in hot and humid environments," Safety and Health at Work, vol. 6, no. 11, pp. 1-10, 2017.

[6] D. J. Brake and G. P. Bates, "Fluid losses and hydration status of industrial workers under thermal stress working extended shifts," Occupational and Environmental Medicine, vol. 60, no. 2, pp. 90-96, 2003.

[7] R. Pedram, K. C. Kocsis, and M. Sunkpal, "Sensitivity analysis of the effect of airflow velocity on the thermal comfort in underground mines," Journal of Sustainable Mining, vol. 15, no. 4, pp. 175-180, 2016.

[8] B. You, C. Wu, J. Li, and H. Liao, "Physiological responses of people in working faces of deep underground mines," International Journal of Mining Science and Technology, vol. 24, no. 5, pp. 683-688, 2014.

[9] M.-c. He, "Application of HEMS cooling technology in deep mine heat hazard control," Mining Science and Technology (China), vol. 19, no. 3, pp. 269-275, 2009.

[10] A. E. Krasnoshtein, B. P. Kazakov, and A. V. Shalimov, "Mathematical modeling of heat exchange between mine air and rock mass during fire," Journal of Mining Science, vol. 42, no. 3, pp. 287-295, 2006.

[11] A. P. Sasmito, J. C. Kurnia, E. Birgersson, and A. S. Mujumdar, "Computational evaluation of thermal management strategies in an underground mine," Applied Thermal Engineering, vol. 90, no. 5, pp. 1444-1150, 2015.

[12] R. Anderson and E. D. Souza, "Heat stress management in underground mines," International Journal of Mining Science and Technology, vol. 27, no. 4, pp. 651-655, 2017.
[13] S. P. Zhang, J. Qin, and G. Chen, "Heat transfer analysis on double-skin air tube in ventilation of deep mine heading face," Procedia Engineering, vol. 26, pp. 1626-1632, 2011.

[14] A. Habibi, R. B. Kramer, and A. D. S. Gillies, "Investigating the effects of heat changes in an underground mine," Applied Thermal Engineering, vol. 90, no. 5, pp. 1164-1171, 2015.

[15] Y. Zhang, Z. Wan, B. Gu, H. Zhang, and P. Zhou, "Finite difference analysis of transient heat transfer in surrounding rock mass of high geothermal roadway," Mathematical Problems in Engineering, vol. 2016, Article ID 8951524, 7 pages, 2016.

[16] P. Duda, "Finite element method formulation in polar coordinates for transient heat conduction problems," Journal of Thermal Science, vol. 25, no. 2, pp. 188-194, 2016.

[17] J. J. del Coz Díaz, P. J. García Nieto, C. Betegón Biempica, and M. B. Prendes Gero, "Analysis and optimization of the heatinsulating light concrete hollow brick walls design by the finite element method," Applied Thermal Engineering, vol. 27, no. 89, pp. 1445-1456, 2007.

[18] C. Guo, X. Nian, Y. Liu, C. Qi, J. Song, and W. Yu, "Analysis of $2 \mathrm{D}$ flow and heat transfer modeling in fracture of porous media," Journal of Thermal Science, vol. 26, no. 4, pp. 331-338, 2017.

[19] J. Kim and H. Choi, "An immersed-boundary finite-volume method for simulation of heat transfer in complex geometries," Ksme International Journal, vol. 18, no. 6, pp. 1026-1035, 2004.

[20] Q. Wu, Y. P. Qin, L. Guo, and Q. Y. Wu, "Calculation of the heat emitting from the wall rock at drifting face with finite element method," China Safety Science Journal, vol. 12, no. 6, pp. 33-36, 2002. 